[ documento ]

\title{
Cultura pela culatra
}

José Miguel Wisnik

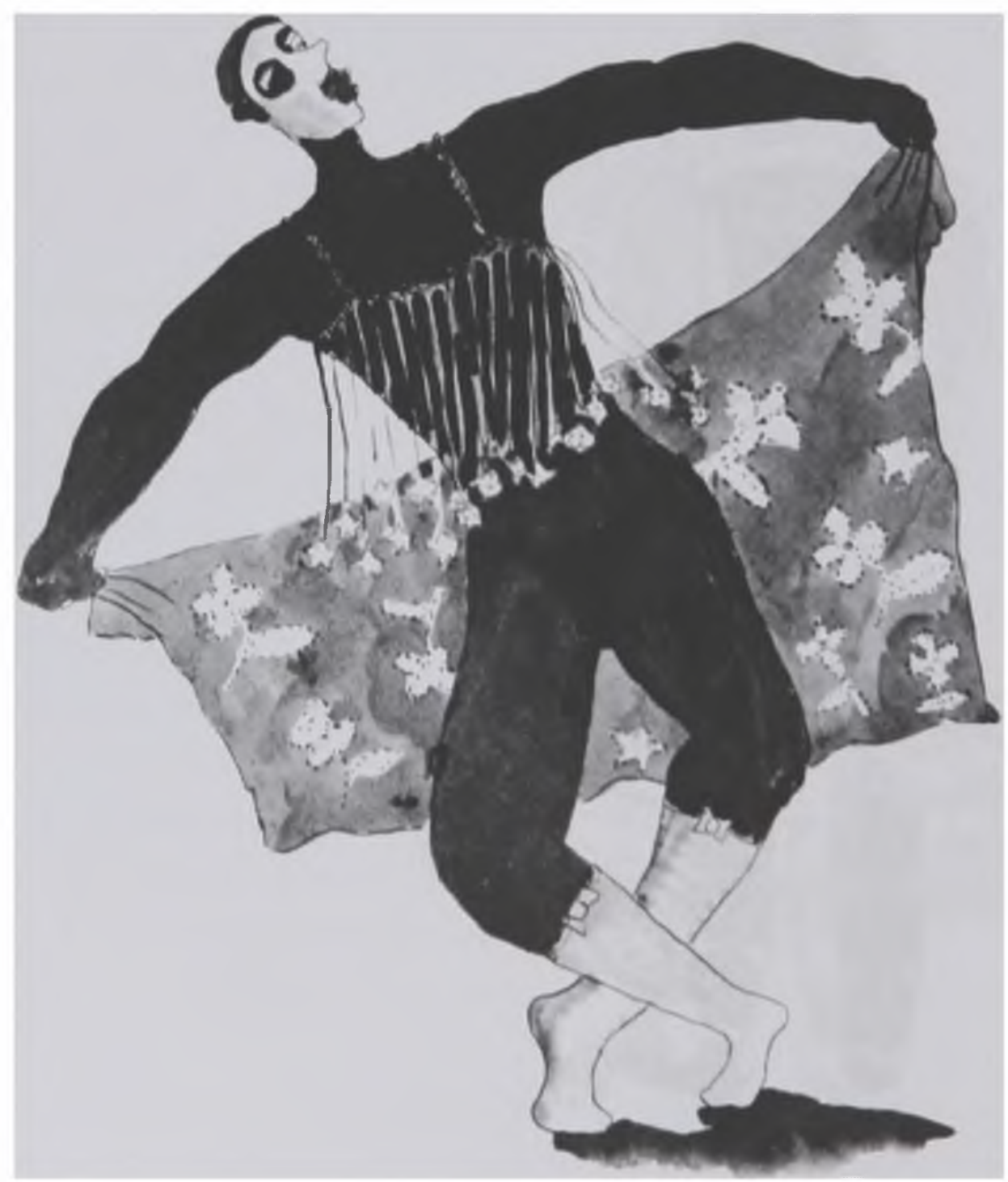


Resumo O autor relaciona a discussão envolvendo a cultura popular e a cultura erudita, desenvolvida ao longo da obra de Mário de Andrade, com episódio de Macunaíma em que o amuleto tribal do herói transforma-se em objeto da coleção (mercado/museu) do negociante enriquecido. A relação permite sugerir

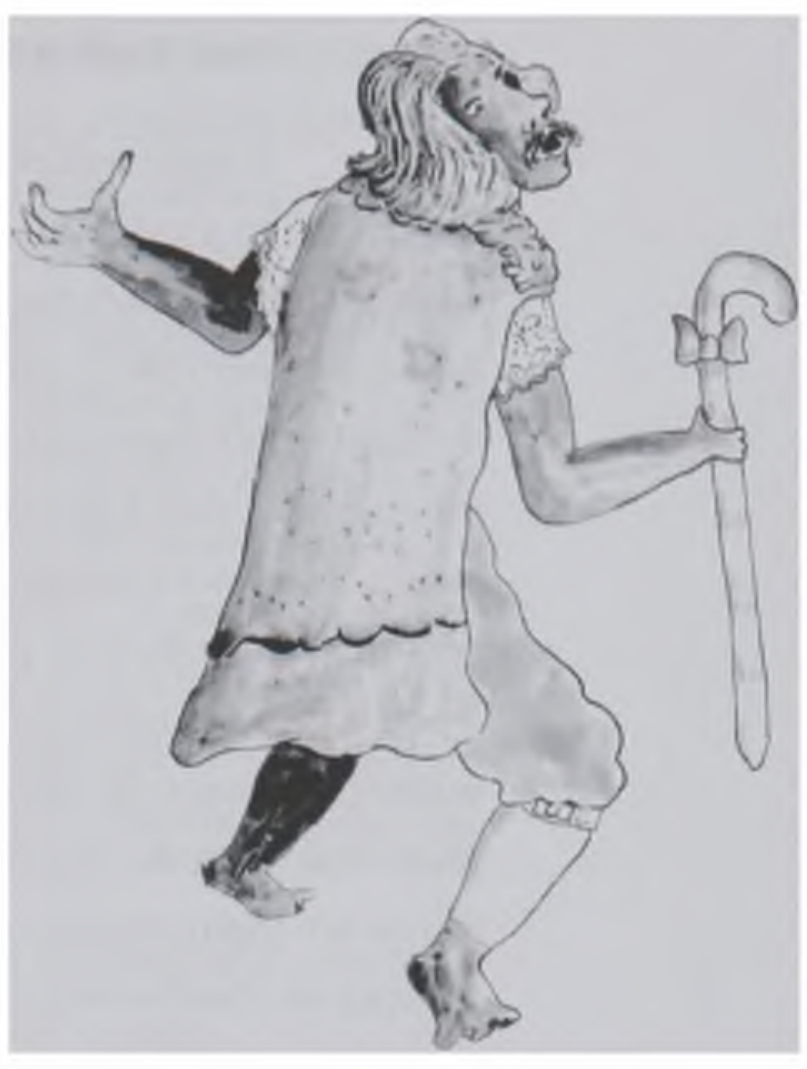
um contraponto entre o contexto cultural em que Mário atuava e o contexto cultural contemporâneo.

Abstract The author relates to the debate concerning popular and scholar culture in Mário de Andrade's work. He considers specially the Macunaíma's episode when the heroe's tribal talisman becomes a piece from the enriched merchant's collection (market/museum). The article allows suggest a counterpoint between Mário's cultural context and the contemporary one.

Palavras-chave literatura - cultura popular e erudita - Mário de Andrade - Macunaíma Keywords literature - popular and scholar culture - Mário de Andrade - Macunaíma 


\section{Nota explicativa}

O texto a seguir, que ensaia uma breve leitura de um episódio de Macunaíma, foi escrito a partir de uma circunstância precisa: o convite para participar do site que acompanhou a grande exposição sobre o livro de Mário de Andrade, realizada no SESC Belenzinho em 1999. A situação exigia, de fato, um posicionamento sobre o lugar atual do literário, ali onde o texto modernista, hoje um clássico, tornava-se ao mesmo tempo espetáculo e objeto de manipulação midiática. Por um lado a concepção da exposiçāo, que contava com a imaginação livre e muito viva de Gisela Magalhães, e que presentificava momentos do livro com atores, cenários e grandes espaços, aludia intensamente à narrativa, ao mesmo tempo em que a dissipava, quase que necessariamente, numa espécie de parque de eventos dividido em quadros. Por outro, o site propunha uma reapropriação do texto segundo as modalidades do suporte informático/internético, onde se põe em jogo o destino do "livro depois do livro" (tema de pesquisa, aliás, de sua organizadora, Giselle Beiguelman).

Convidado a fazer uma leitura de Macunaíma, talvez mais como músico do que como professor de literatura, entre artistas gráficos e plásticos, num meio tendente às oralizações e aos letrismos, me vi tomado pelo sentimento orgulhosamente deslocado da revanche verbal, isto é, pelo desejo de devolver o texto a seu meio originário, em que palavras falam com palavras. Daí a escolha de uma passagem do livro (o episódio A francesa e o gigante) na qual me pareceu ser possível ler, entre outras coisas, um recado de Macunaíma às circunstâncias contemporâneas que cercam a exposição sobre ele mesmo (para esta edição, fiz pequenas alterações e acrescentei notas).

Sem me reconhecer no apologeta dos novos meios nem no literato reativo aos computadores e aos meios de massa, me interessa de fato o livro depois do livro, para além do livro, sempre o livro: transformações dessa que segue sendo a mais complexa das realidades virtuais. E nesse ponto, não há o que temer: a atualidade de uma obra se mostra quando as condições que a geraram, as expectativas e apostas do autor, o chão concreto em que ela se formulou, se deslocam contra ela mas, ao mesmo tempo, graças à sua complexidade interna, a favor dela.

Quando escreveu Macunaíma Mário de Andrade tinha um projeto estético explícito, no qual a rapsódia do "herói sem nenhum caráter" se inscreve: basear a arte brasileira na cultura popular rural. Isso significava pesquisar lendas, provérbios, repentes, reisados, cocos, aboios, congos e congados para fazer do imenso reservatório do folclore rural brasileiro a matéria-prima e a referência 
técnica da cultura letrada. Mário pôs nesse projeto um empenho normativo e doutrinário, como se pode ver no Ensaio sobre a música brasileira, onde diz que artista que não se dedicar à formação de uma cultura de expressão nacional com base no folclore é "pedregulho na botina" a ser jogado fora. Pode-se dizer que seu intuito era encontrar o "caráter" de um Brasil "sem caráter" unindo dois mundos separados por um fosso abissal: o da cultura erudita transplantada de base européia e o das culturas populares espalhadas pelo território brasileiro, que testemunhavam a criação inconsciente do povo através dos séculos de colonização.

Tratava-se, portanto, de unir o popular e o erudito, o oral e o escrito, numa síntese que resultaria ao mesmo tempo de muita pesquisa (coisa que ele diz nos textos programáticos) e do pulo do gato da intuição artística (coisa que ele só diz fazendo, nos textos criativos, fora do alcance dos imitadores epigonais que se apegam a receitas).

Friso aqui o detalhe decisivo: para o autor de Macunaima a chave de tudo (que tiraria a produção intelectual da sua irrelevância porque a colocaria a serviço de uma causa nacional) estaria no compromisso da cultura letrada com a cultura popular brasileira, entendida necessariamente como cultura rural, artesanal, anônima e coletiva. Exemplificando: embora encare sem preconceitos, no Ensaio, a influência do jazz sobre o maxixe,' os objetos de sua escolha crítica não serão propriamente Donga, Pixinguinha, Sinhô ou Noel, músicos do nascente mercado de música urbano-industrial, mas Chico Antônio, coqueiro repentista do Nordeste; não o samba carioca mas o samba rural paulista; não o futebol mas o bumba-meu-boi.

A aposta era discutível, embora isso não fosse evidente nos anos 20 : num Brasil que se industrializava, Mário jogou toda a sua intenção programática num projeto de cultura de base artesanal e pré-industrial (em contradição latente com o seu próprio modernismo militante de autor da Paulicéia desvairada). Pode-se dizer no entanto que essa escolha expressa nele, mais do que um purismo folclórico (aliás incompatível com as misturas paródicas de Macunaíma), o sentimento de uma encruzilhada parecida com aquela que já se aventou sobre Raízes do Brasil de Sérgio Buarque de Holanda: se o Brasil se moderniza deixa de ser Brasil (porque perde, junto com o atraso, as singularidades secretas de sua forma-

\footnotetext{
1 "Os processos do jazz estāo se infiltrando no maxixe. Em recorte infelizmente não sei de que jornal guardo um samba macumbeiro, Aruê de Changô de João da Gente que é um documento curioso por isso. E tanto mais curioso que os processos polifônicos e rítmicos de jazz que estão nele não prejudicam em nada o caráter da peça. De certo os antepassados coincidem..." Ensaio sobre a música brasileira. São Paulo: Martins, 1962, p. 25.
} 
ção, expressas no tesouro vivo e perecível da cultura popular); se o Brasil permanece Brasil não se moderniza (e se arrisca a perecer de suas feridas abertas e auto-devorantes) $)^{2}$

Oswald de Andrade deu a esse dilema uma orientação positiva: devorando o que o devora, o Brasil seria, quanto mais moderno, tanto mais Brasil (encontramos formulações parecidas nas considerações de Caetano Veloso sobre o Tropicalismo) ${ }^{3}$ Já Mário de Andrade sofre o dilema de uma forma agônica, conflituada e interrogativa. Pode-se supor, lendo Macunaíma, que ele sentisse ou intuísse que era preciso entrar na modernidade da indústria sem perder a identidade popular forte, difusa e ao mesmo tempo perpetuamente instável num país paradoxalmente vocacionado para a modernidade (porque sua identidade sempre foi inseparável da diferença) e sempre incapaz de tornar-se propriamente moderno (porque, entre outras coisas, não põe e não conhece limites, nem ou principalmente os seus próprios). Essa é exatamente, aliás, a ferida do herói "sem nenhum caráter" na sua "dialética rarefeita entre não-ser e ser outro": tribal e moderno, selvagem e citadino, "tupi tangendo alaúde" não tem para onde voltar e nem para onde ir. Pode-se mesmo dizer que não sabe ficar onde chegou, no transe em que se despedaça e se transforma em estrela (e em livro).

Dar forma a esse impasse e a esse enigma, ao mesmo tempo agônico e libertador, é um dom de Macunaíma, texto "profético" - no sentido de que diz cifradamente coisas que a realidade não pára de repor.

Agora ao ponto: quando escolheu a cultura popular rural e ostensivamente não-urbana como o outro salvador da cultura brasileira, Mário tomou como seu modelo a cultura fora-do-mercado, a cultura no avesso da mercadoria, a cultura como o império da não-mercadoria, produzida pelo artista anônimo e coletivo em oposição à "influência deletéria do urbanismo" onde se misturam as influências estrangeiras e os chamativos comerciais e industriais.

Essa oposição ao mercado (embora não formulada nesses termos) o jogava implícita ou explicitamente para um projeto de Estado: o matrimônio com a cultura popular exigiria uma política de Patrimônio, a pesquisa da cultura folclórica faria com que ela fosse trazida para o Museu lobedecendo àquele dita-

2 NOVAIS, Fernando. "De volta ao homem cordial" Iornal de resenhas (1.5.1995, n², p. 2). Folha de S. Paulo; Discurso Editorial; USP

3 "Às vezes algumas afirmações instigantes de Ariano Suassuna sobre o Brasil a mim me soam aparentadas com a famosa frase de Salazar 'prefiro ver Portugal pobre do que Portugal diferente' Ao contrário, eu penso que o Brasil deve tornar-se o mais diferente de si mesmo que lhe for possível, para encontrar-se. Conferência inédita no MAM. Rio de Ianeiro. 
me da ordem das coisas segundo o qual, na formulação de Edoardo Sanguinetti na altura dos anos 60, o destino da arte no capitalismo é o mercado ou o museu).

Cifradamente Macunaíma fala, bem a propósito, dos impasses contidos nessa avaliação da cultura: a pedra muiraquitã, amuleto do herói, perdida no mundo tribal, cai no mercado-museu do mercador gigante "comedor de gente" A intriga (mas também o destino implícito do próprio livro e da cultura) gira em torno dessa pedra-de-toque perdida, dotada originariamente de um valor-de-uso mágico (como a arte), e jogada agora numa suspensão sem lugar entre o povo, o mercado e o museu

Mário sofreu pessoalmente esse drama, e às vezes suspeita-se mesmo que morreu disso: dejetado do Departamento de Cultura que dirigia, no primeiro tranco do Estado Novo, assiste por outro lado, impotente, à mercantilização crescente da cultura. Mas a questão é muito mais do que episódica e biograficamente datada (embora se concretize sempre em relações pessoais): num tempo - o nosso - em que a cultura envolveu-se, toda, na esfera do mercado (mídia, marketing, mershandising, patrocínio), e em que nenhum objeto artístico parece poder passar sem a marca de uma logomarca, o projeto fracassado de Mário se realiza exatamente pelo avesso, ferindo a cultura pela culatra.

Senão vejamos.

No outro dia (...) o herói percebeu que xetrara mesmo duma vez e nunca mais que podia aparecer na rua Maranhão porque agora Venceslau Pietro Pietra já o conhecia bem. Imaginou imaginou e ali pelas quinze horas teve uma idéia. Resolveu enganar o gigante. Enfiou um membi na goela, virou Jiguê na máquina telefone e telefonou pra Venceslau Pietro Pietra que uma francesa queria falar com ele a respeito da máquina negócios. $O$ outro secundou que sim e que viesse agorinha já porque a velha Ceiuci tinha saído com as duas filhas e podiam negociar mais folgado.

A cena está no capítulo vı de Macunaíma: A francesa e o gigante. Venceslau Pietro Pietra (mascate imigrante enriquecido, que é também o gigante Piaimã) tem a pedra muiraquitã em seu poder. Macunaíma quer recuperá-la mas já fracassou (literalmente frito) na sua primeira incursão ao palacete da rua Maranhão (da qual só se salvou graças aos proverbiais atributos mágicos do irmão mais velho, Maanape feiticeiro). Agora ataca novamente, não mais como caçador do mato (que enfrentasse numa luta tribal o gigante Piaimã), mas metamorfoseado numa curiosa espécie de homem-de-negócios em travesti: travestide-negócios. Tudo pela troca das trocas: trata-se (tratante) de falar a mesma linguagem do negociante novo rico, aproveitando o câmbio favorável de macho para 
fêmea num roça-roça de sexos implícitos. Voz melíflua e aflauteada pelo membi (flauta-tupi) simulado na garganta. O irmão preto Jiguê no papel colonial de "muleque de recado" é transformado, rápido e repente, no objeto urbano-industrial máquina telefone Ainda não há secretária executiva bilíngue: o próprio homem de negócios atende, morde a isca e se propõe e dispõe a negociar com a francesa em randevu folgazão na casa-de-família vazia, que naquele momento é também casa vazia-de-família

Então Macunaíma emprestou da patroa da pensão uns pares de bonitezas, a máquina ruge, a máquina meia-de-seda, a máquina combinação com cheiro de casca-sacaca, a máquina cinta aromada com capim cheiroso, a máquina decoletê úmida e patchuli, a máquina mitenes, todas essas bonitezas, dependurou dois mangarás nos peitos e se vestiu assim. Pra completar inda barreou com azul de pau campeche os olhinhos de piá que se tornaram lânguidos. Era tanta coisa que ficou pesado mas virou numa francesa tão linda que se defumou com jurema e alfinetou um raminho de pinhão paraguaio no patriotismo para evitar quebranto. E foi no palácio de Venceslau Pietro Pietra. E Venceslau Pietro Pietra era o gigante Piaimã comedor de gente.

O jogo de cena: uma verdadeira parafernália de fetiches femininos em strip-tease às avessas. lá de há muito Macunaíma depreendeu pelo espírito da coisa que na cidade tudo é máquina: se no mundo tribal cada coisa que existe é habitada por espíritos míticos, na máquina-cidade cada espírito é habitado por coisas, coisas que fazem coisas e coisas que troca-trocam coisas. É certamente a seus olhos (olhinhos de piá agora se quebrando lânguidos sob o efeito da máquina-maquiage) um tipo de animismo um pouco diferente do animismo selvagem: em vez de conjurar e esconjurar os bons e os maus espíritos, as coisas, animadas pelo comércio entre as próprias coisas, são máquinas de trocas trocadas pela máquina-dinheiro. Mas aqui o fetichismo do mundo animista e selvagem se confunde com o fetichismo da máquina-mercadoria, pois é tudo sedução do feitiço e coisa feita. E no caso da cena acima, quando o herói completa seu trans-vestido de francesa, era tanta coisa feita (maquinaria de feitiço fetichismo fazendo surgir a mulher fatal dos efeitos dissimulados) que ela mesma se defuma com jurema (planta feiticeira) e se inventa para si um amuleto caprichado (raminho de pinhão paraguaio) espetado num hipotético lugar metonímico, ideal ou ideológico (o patriotismo). Fetichismo do amuleto tribal (a muiraquitã), fetichismo da sedução sexual (o travesti), fetichismo da mercadoria (a coleção do gigante negociante colecionador) ${ }^{4}$

4 Tomo a expressão "coisa feita" no duplo sentido sugerido, de uma exposição do professor 
(...) Lá chegado encontrou o gigante no portão, esperando. Depois de muitos salamaleques Piaimã tirou os carrapatos da francesa e levou-a pra uma alcova lindíssima com esteios de acaricoara e tesouras de itaúba. $O$ assoalho era um xadrez de muirapiranga e pau-cetim. A alcova estava mobiliada com as famosas redes brancas do Maranhão. Bem no centro havia uma mesa de jacarandá esculpido arranjada com louça branco-encarnada de Breves e cerâmica de Belém, disposta sobre uma toalha de rendas tecidas com fibras de bananeira. Numas bacias enormes originárias das cavernas do rio Cunani fumegava tacacá com tucupi, sopa feita com um paulista vindo dos frigoríficos da Continental, uma jacarezada e polenta. Os vinhos eram um Puro de Ica subidor vindo de Iquitos, um Porto imitação, de Minas, uma caiçuma de oitenta anos, champanha de São Paulo bem gelada e um extrato de jenipapo famanado e ruim como três dias de chuva. E inda havia dispostos com arte enfeitadeira e muitos recortados de papel, os esplêndidos bombons Falchi e biscoitos do Rio Grande empilhados em cuias dum preto brilhante de cumaté com desenhos esculpidos a canivete, provindas de Monte Alegre.

As relíquias do Brasil: madeiras nobres da mata, artesanatos nortenordestinos, culinária indígena e urbano-antropófaga, comes e bebes fabricados nos confins da Amazônia, em Minas, em São Paulo, no Sul. O regatão enriquecido Venceslau Pietro Pietra sublimou suas andanças de mascate colecionando o país todo nos objetos indicativos de sua casa-palacete, que se constitui num Brasil em miniatura, e de sua propriedade. A descrição não deixa de ter algo a ver com os próprios saraus e salões de Dona Olívia Guedes Penteado, ou seja, da burguesia industrial do café paulista que patrocinou o modernismo, e nos quais "a cozinha, de cunho afrobrasileiro, aparecia em almoços e jantares perfeitíssimos de composição" (como nos conta, na conferência sobre o movimento modernista, o próprio Mário de Andrade) ${ }^{5}$ Iuntar mercado e museu, indústria e arte, produção e patrocínio, colecionar o Brasil, será um atributo dos Prados, Penteados e Amarais, a oligarquia futurista paulista, mas também mais

José Antonio Pasta Junior. Nela combina-se agudamente a expressão corrente, ligada ao mundo do fetichismo animista, com os traços do fetichismo da mercadoria, no qual, segundo a análise de Marx, as "características materiais e propriedades sociais inerentes aos produtos do trabalho" se dissimulam, assumindo "a forma fantasmagórica de uma relação entre coisas" ("O fetichismo da mercadoria: seu segredo" O Capital Livro Primeiro). É possível vislumbrar aí um caminho de leitura para a trama de fetichismos (arcaico e moderno, mítico, sexual e mercadológico, antropológico, psicanalítico e econômicol que se compõe em Macunaíma.

5 "O movimento modernista" In: Aspectos da literatura brasileira. São Paulo: Martins, 1974, p 239. 
tarde, de outro modo, da família do conde Matarazzo, aqui propriamente o comerciante imigrante enriquecido cujo sobrenome ficou associado ao mercado (das indústrias) e ao museu (a Bienal de São Paulo). Esse arquétipo e entidade sociológica paulista reencarnar-se-á por sua vez, em tempos de cultura de massa, em Silvio Santos, protótipo do comerciante imigrante enriquecido, resguardado no recesso do seu império empresarial-midiático, detendo em seu poder o sortilégio do amuleto-fetiche da fortuna dentro do Baú da Felicidade (cuja sede cerca literalmente, com um cinturão engolidor de propriedade-poder, situado no Bexiga, o Teatro Oficina oswaldiano e macunaímico). Algo desse perfil façanhudo, associado a origens e trajetória semelhantes, é por sua vez reconhecível na figura de Paulo Salim Maluf (o qual, e tal qual Piaimã, cada vez que apanha corre invariavelmente para a Europa). Sem falar no poder emblemático de que o acaso investiu a rua Maranhão, residência pessoal do Presidente sociólogo.

Mas não nos confundamos com os vários avatares de Pietro Pietra. No Macunaima ele faz uma aparição chiquíssima, como acabamos de ver na descrição da alcova

A francesa sentou numa rede e fazendo gestos graciosos principiou mastigando. Estava com muita fome e comeu bem. Depois tomou um copo de Puro pra rebater e resolveu entrar no assunto de chapéu-de-sol aberto. Foi logo perguntando si o gigante era verdade que possuía uma muiraquitã com forma de jacaré. $O$ gigante foi lá dentro e voltou com um caramujo na mão. E puxou pra fora dele uma pedra verde. Era a muiraquitã! Macunaíma sentiu um frio por dentro de tanta comoção e percebeu que ia chorar. Mas disfarçou bem perguntando si o gigante não queria vender a pedra. Porém Venceslau Pietro Pietra piscou faceiro dizendo que vendida não dava a pedra não. Então a francesa pediu suplicando pra levar a pedra de emprestado pra casa. Venceslau Pietro Pietra mais uma vez piscou faceiro falando que de emprestado não dava a pedra também não.

- Você imagina então que vou cedendo assim com duas risadas, francesa? Qual!

- Mas eu estou querendo tanto a pedra!...

- Vá querendo!

- Pois tanto se me dá como se me dava, regatão!

- Regatão uma ova, francesa! Dobre a língua! Colecionador é que é!

Depois da aparição, tão desejada, da muiraquitã, que tem o condão de despertar as profundas emoções que nela se concentram, vem a negociação, desde o início anunciada. A francesa joga charme e o regatão regateia, recusan- 
do. Fetiche contra fetiche num desenho lógico, mas sem moeda de câmbio capaz de trocar muiraquitã e sexo. No impasse, a francesa rebaixa o mercador: regatão! Na resposta, o regatão eleva seu preço e revela a nova chave do seu valor: colecionador é que é! Trata-se de um colecionador célebre, como ele se apresenta a seguir, tendo mostrado o exemplário inumerável do seu acervo (Tinha turquesas esmeraldas berilos seixos polidos, ferragem com forma de agulha, crisólita pingo d'água tinideira esmeril lapinha ovo-de-pomba ... numa lista sem fim de pedras guardadas no seu grajaú sem fundo). Não é difícil discernir um outro sentido nesse colecionador literal: a palavra remete à esfera da arte, e o que eram antes as mercadorias do negociante tornaram-se agora peças de museu, funcionalmente apartadas do corre-corre do mercado e suspensas no valor quase inapreçável de sua aura. À parte as mercadorias, o mercador coleciona como que obras de arte, entre as quais, jóia da coleção, reina inegociável a pedra muiraquitã (mercadoria que quintessencia o seu valor originário de puro fetiche).

Não há como falar aqui dos quiproquós que se seguem, quando Venceslau quer cobrar à risca as promessas implícitas da francesa, que por sua vez afeta surpreender-se com a literalidade do seu Outro (Será que o gigante imagina que sou francesa mesmo!... Cai fora, peruano senvergonha!)

O fato é que a cena engraçada capta algo da estrutura das relações que se fixaram no mundo cultural que conhecemos, em que museu e mercado passaram a manter uma distinção muito tênue. Nesse quadro, só temos a ganhar em reconhecer que gigante $e$ francesa preenchem as funções de patrocinador e patrocinado, curador e curado, entre os quais as noções de arte e cultura estão muitas vezes no lugar do puro fetiche: sedução recíproca que se esvai no jogo de espelhos da vitrine do marketing cultural. Nesse jogo, os artistas vieram perdendo a capacidade da iniciativa, e a cultura curada tendeu a tornar-se, se não é, uma espécie de mal incurável

Para mim, no entanto, a questão continua sendo: mirar no valor singular de uso e de troca da produção cultural, naquilo em que esse valor é irredutível aos do mercado e do museu, correndo fora - se não do mercado - de toda espetacularidade vazia. O brilho inútil da constelação em que Macunaíma se transformou, banzando no céu solitário, não se confunde com o "brilho inútil" dos fetiches descartáveis que introjetaram a forma mercadoria no âmago do âmago: trata-se de uma inutilidade oposta a esta, aquela que guarda o brilho das coisas vivas e suspensas, estrelas mortas que mandam luz aos vivos porque mantêm os laços tênues e indescartáveis entre o que foi, é e será (ou nunca será) vivido. Os fios em que se dão esses laços podem ser chamados de cultura, e é neles 
que se ata e desata, enigmática e escapadiça, a pedra-amuleto objeto-do-desejo e fetiche muiraquitã

Não posso deixar de colocar o colar - feito desses mesmos fios - no meu próprio pescoço, e nem de passá-lo adiante, ao terminar esse texto feito especialmente para o site da exposição do SESC sobre Macunaíma. Acontece que essa exposição, cheia de vida, de coisas e de coisas vivas, atesta a atualidade do livro, não só porque a exposição fala dele, mas porque - pode-se dizer também - ele, o livro, fala dela. Quando a política cultural de Estado tornou-se anódina, ou confundida com o crivo do mercado, em São Paulo o SESC (Serviço Social do Comércio: grajaú sem fundo da coleção do comerciante) tornou-se mercadomuseu vivo e agente de uma política cultural "de Estado" O modo singular como isso se deu faz dele uma combinação ambígua de "herói da nossa gente" (agente depositário da cultura que não se confunde com o puro mercado) e de Gigante - há um gigantismo inequívoco nos seus poderes e projetos, não só no tamanho mas na natureza empresarial do poder de fogo (a seu lado, o gigante Itaú Cultural, banco que guarda a pedra no nome, confirma sintomaticamente $o$ mesmo balancê entre cultura e mercado).

Esse comentário final não se pretende corrosivo nem apologético: tratase de falar da atualidade objetiva de um livro que se torna objeto de consagração mas que, em vez de virar pedra passiva da coleção de clássicos modernistas, continua colocando problema e, como cobra que morde o rabo, o seu e o nosso, renascendo novo de novo. Não é o caso de tentar, aqui, uma análise das vicissitudes atuais da cultura curada. Mas de sugerir que Macunaíma contém por dentro um modelo sugestivo de reflexão sobre esta, num momento em que o brilho intermitente da Ursa Maior, "pai dos vivos" na imagem final de Macunaíma, tremelica como nunca entre a estrela e o penduricalho

José Miguel Wisnik é professor de Literatura Brasileira da Universidade de São Paulo e músico. Publicou Coro dos contrários: a música em torno de 22 [Duas Cidades, 1977] e O som e o sentido [Cia. das Letras, 1989], entre outros. 
As aquarelas de Cicero Dias reproduzidas nesta seçāo foram gentilmente cedidas pelo Instituto de Estudos Brasileiros da USP.

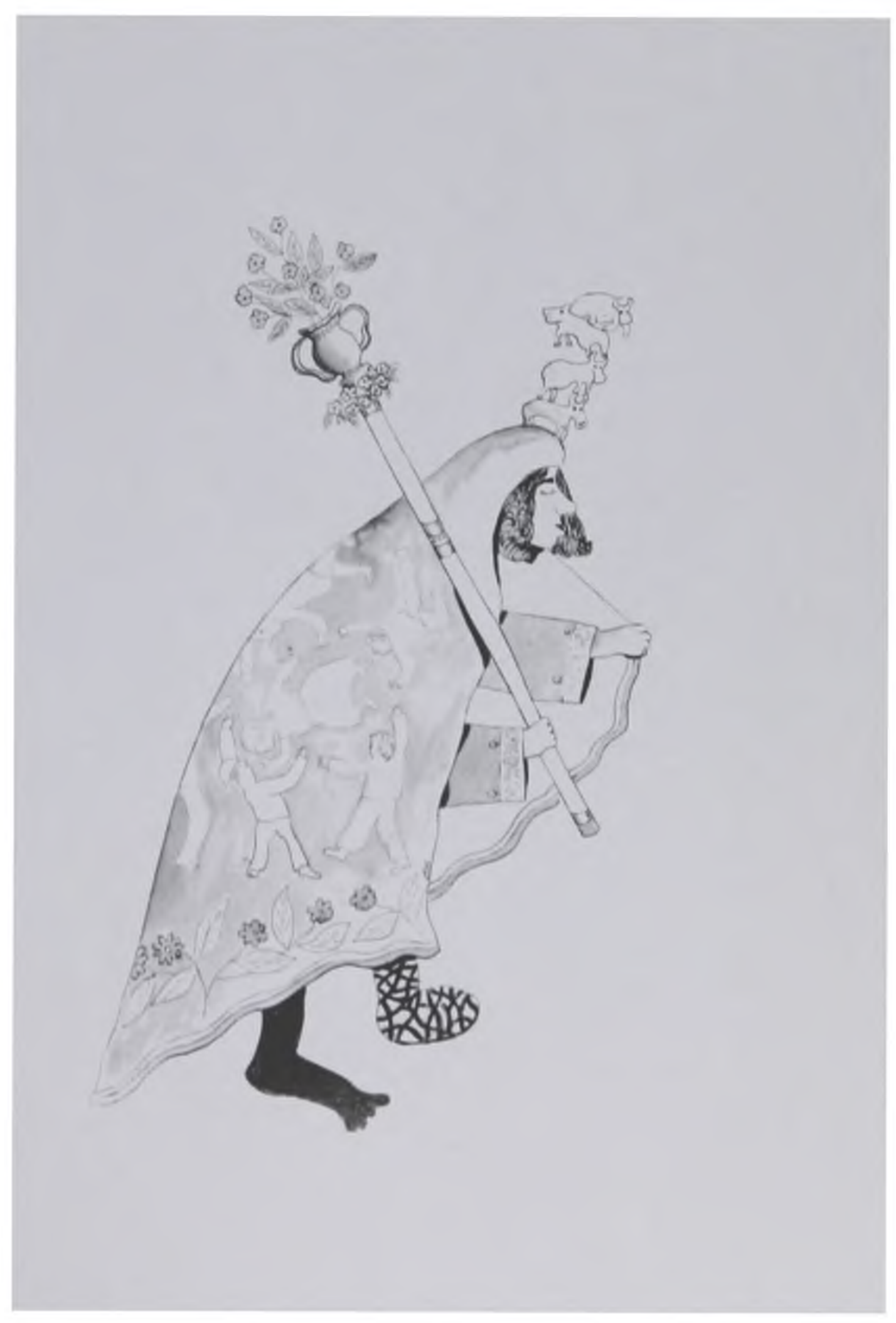

